\title{
Editorials
}

\section{The Acoustic Neuroma Saga}

The hundred years since May 1895 when Annendale first successfully removed an acoustic neuroma in Edinburgh, have been marked by continuous improvement in being able to cure patients of this benign but in years past very lethal lesion. My own interest in this lesion spans only one third of those years, but as I look back, the remarkable changes in diagnosis and surgery of these tumours has been astounding.

I remember as resident at Los Angeles County Hospital reading about acoustic neuromas. The articles all stressed the need for early diagnosis and removal. At the time I was tutored by a remarkable otolaryngologist, Gilbert Roy Owen, who had a special interest in temporal bone X-ray. He stressed the then revolutionary idea of checking the internal auditory canals by X-ray of all patients with unilateral hearing loss. At that time acoustic tumours were rarely diagnosed until the patient developed papilloedema or fifth nerve findings.

During the first year of my practice a healthy 45 year-old fireman presented with a unilateral hearing loss and his X-rays showed considerable enlargement of the internal auditory canal on the side of the hearing loss. I promptly sent him to a neurosurgical colleague assuming that my early diagnosis would lead to early removal. I soon received a call from the neurosurgeon, telling me that he agreed with my diagnosis, but he had advised watchful waiting. He told me that surgery meant 100 per cent chance of total facial paralysis and a high risk of fatality. In 1956 the California Tumour registry indicated a 40 per cent mortality rate for acoustic tumour removal. It just did not seem reasonable to trade a little hearing loss and tinnitus for this dismal prognosis and it was possible the tumour might not grow.

Unfortunately the tumour did grow and within the year the patient developed headache and papilloedema. I observed the long and tedious surgery with the patient in the seated position and was horrified that the patient never regained consciousness and died several days later. In a later discussion of the case the neurosurgeon told me that I had to realize the patient had a very big tumour.

It became apparent to me that there was a great dilemma between early diagnosis and early removal of acoustic neuromas. It became obvious that the key to reduced mortality was the facial nerve. If we could save the facial nerve, patients would probably be amenable to early surgery.
Fortunately at this time (1956) the operating microscope was just being introduced to otology. My brother, Howard, had become aware of some very interesting surgery called tympanoplasty and had visited Professor Wullstein in Wurtzburg to observe this surgery. As far as I know, Howard was the first to import a Zeiss operating microscope into the U.S. In order to learn more about the possibilities of temporal bone microsurgery, Howard placed the microscope in the L.A. County Morgue. Howard, for several years had been using the facilities and cadaver material of the morgue to teach fenestration surgery. During my first years in practice, in the evenings, with my wife June acting as my surgical nurse, I was able to explore a number of surgical approaches to the temporal bone using this wonderful new operating microscope. I soon found that using irrigation suction and diamond stones (techniques I had learned years earlier as a dentist) the facial nerve could be approached and dissected out of the temporal bone.

So in the early 1960 s my experience with acoustic neuroma patients and my growing experience with microsurgery for tympanoplasty and stapedectomy, convinced me that microsurgery techniques were the key to saving the facial nerve in acoustic neuroma removal.

I teamed up with several neurosurgeons and the first approaches to acoustic neuromas using microsurgical procedures were done through the middle fossa. I finally found a young neurosurgeon, Bill Hitselberger, who was very willing to learn and work with me and together we developed the translabrynthine approach to acoustic neuromas.

After publishing some of our early work, neither of us was prepared for the turf battles that erupted. Several of the neurosurgeons on the staff of the hospital where we were doing our acoustic neuromas became upset that an otologist was crossing the sacred barrier, the dura, that lined the medial surface of the temporal bone. They got a resolution passed by the medical executive committee that all acoustic neuroma patients admitted to the hospital would be examined by a neurosurgeon and they would decide the surgical approach that was to be used. It was obvious that this would always be a suboccipital approach without a microscope. By this time because of our early publications, Bill and I were getting referrals of acoustic neuroma patients. Obviously we could not accept referrals for our type of surgery if 
the patients were to be taken over by other neurosurgeons.

Fortunately, Howard, as a senior member of the staff came to our rescue and after several very tense meetings it was decided that either Howard, Bill and I would resign or the neurosurgeon who had started the proceedings would resign. The controversy was finally resolved in our favour and the neurosurgeon resigned.

In the years that followed Bill and I taught a number of our fellows acoustic neuroma surgical techniques. A number of our students experienced similar turf disputes. As so well expressed by the late Dr. Gardner, a leading neurosurgeon from Cincin-

The Journal of Laryngology and Otology is pleased to be associated with the commemoration of the centenary of the removal of the first acoustic neuroma (vestibular schwannoma) tumour by Thomas Annandale on 3 May 1895. It is fitting that the Editorial should be written by the founder of modern otoneurosurgery, Dr William House. His contribution to this field is second to none. The remarkable change in mortality and facial nerve preservation associated with the translabyrinthine approach cannot be underestimated. Dr House has trained otologists from all over the world and has not only changed the outlook for those patients suffering from cerebellopontine angle tumours but has also opened up the whole field of microsurgical approach to the skull base.

Professor Richard Ramsden traces the historical development of vestibular schwannoma surgery, $\mathrm{Dr}$ Mario Sanna and his colleagues attempt to regularize nati, 'It does not matter who gets the business, so long as the patient does not get the business'.

I am very gratified that today very few would do acoustic neuroma surgery without a microscope, the mortality has fallen to less than half of 1 per cent, and the facial nerve is preserved in 90 per cent of the patients. With today's imaging techniques, tumours of a few millimetres can be diagnosed and the major consideration is no longer the facial nerve, but whether the hearing can be saved.

I wonder what the next 100 years will bring. It may well be as spectacular as the past 100 .

Dr William F. House Los Angeles

the reporting of hearing preservation and David Moffat and Richard Irving review the molecular genetics of vestibular schwannoma. Finally, Professor Laszig and his colleagues report on their experience with a multi-channel auditory brainstem implant used in patients suffering from Neurofibromatosis Type 2.

Thus in the space of a little over thirty years the management of vestibular schwannoma has been transformed. New techniques in imaging can now detect a tumour of no more than a few millimetres in size, means of determining the growth rate of vestibular schwannomas are developing and stereotactic radiotherapy is offering an alternative treatment to surgery. To paraphrase Dr William House what will the next thirty years offer us?

Neil Weir Editor 